\title{
Calpain inhibitor I reduces colon injury caused by dinitrobenzene sulphonic acid in the rat
}

\author{
S Cuzzocrea, M C McDonald, E Mazzon, H Mota-Filipe, T Centorrino, M L Terranova,
} A Ciccolo, D Britti, A P Caputi, C Thiemermann

\begin{abstract}
Institute of
Pharmacology,

University of Messina,

Italy

S Cuzzocrea

A P Caputi
\end{abstract}

William Harvey

Research Institute, St

Bartholomew's and the Royal London School

of Medicine and

Dentistry,

Charterhouse Square,

London EC1M 6BQ

UK

M C McDonald

H Mota-Filipe

C Thiemermann

Department of

Biomorphology,

School of Medicine,

University of Messina,

Italy

E Mazzon

Institute of General

Surgery, University of

Messina, Italy

T Centorrino

M L Terranova

A Ciccolo

Department of Veterinary Medicine and Pharmacology, University of Messina, Italy

D Britti

Correspondence to: S Cuzzocrea, Institute of Pharmacology, School of Medicine, University of Messina, Torre

Biologica-Policlinico

Universitario Via C

Valeria-Gazzi-98100

Messina, Italy.

salvator@www.unime.it

Accepted for publication 14 November 2000

\section{Abstract}

Background and aims-Inflammatory bowel disease is characterised by oxidative and nitrosative stress, leucocyte infiltration, upregulation of expression of intercellular adhesion molecule 1 (ICAM-1), and upregulation of P-selectin in the colon. The aim of the present study was to examine the effects of calpain inhibitor I in rats subjected to experimental colitis. Methods-Colitis was induced in rats by intracolonic instillation of dinitrobenzene sulphonic acid (DNBS).

Results-Rats experienced haemorrhagic diarrhoea and weight loss. Four days after administration of DNAB, the mucosa of the colon exhibited large areas of necrosis. Neutrophil infiltration (determined by histology as well as by an increase in myeloperoxidase activity in the mucosa) was associated with upregulation of ICAM-1 and $P$-selectin as well as high tissue levels of malondialdehyde. Immunohistochemistry for nitrotyrosine and poly (ADPribose) polymerase (PARP) showed intense staining in the inflamed colon. Staining of sections of colon obtained from DNBS treated rats with an anti-cyclooxygenase 2 antibody showed diffuse staining of the inflamed tissue. Furthermore, expression of inducible nitric oxide synthase was found mainly in macrophages located within the inflamed colon of DNBS treated rats. Calpain inhibitor I $(5 \mathrm{mg} / \mathrm{kg}$ daily intraperitoneally) significantly reduced the degree of haemorrhagic diarrhoea and weight loss caused by administration of DNBS. Calpain inhibitor I also caused a substantial reduction in (i) degree of colon injury, (ii) rise in myeloperoxidase activity (mucosa), (iii) increase in tissue levels of malondialdehyde, (iv) increase in staining (immunohistochemistry) for nitrotyrosine and PARP, as well as (v) upregulation of ICAM-1 and P-selectin caused by DNBS in the colon.

Conclusion-Calpain inhibitor I reduces the degree of colitis caused by DNBS. We propose that calpain inhibitor I may be useful in the treatment of inflammatory bowel disease.

(Gut 2001;48:478-488)

Keywords: calpain; calpain inhibitor I; cyclooxygenase; nitric oxide; inflammatory bowel disease; rat

The neutral protease calpain is one of the many intracellular proteins the activity of which is dependent on intracellular calcium levels. To date, two isoforms of calpain have been identified: calpain I (or $\mu$-calpain) and calpain II (or $\mathrm{m}$-calpain), which require low and high micromolar concentrations of calcium for their activation, respectively. ${ }^{12}$ Following activation by calcium, calpain cleaves a specific subset of cellular proteins, including cytoskeletal proteins, membrane receptors, calmodulin binding proteins, $\mathrm{G}$ proteins, protein kinase $\mathrm{C}$ (and other enzymes involved in signal transduction), and many transcription factors, including nuclear factor $\kappa \mathrm{B}(\mathrm{NF}-\kappa \mathrm{B}){ }^{3}$ For example, calpain $I$ inhibitor reduces the degradation of $I \kappa B$ $(\mathrm{I} \kappa \mathrm{B} \alpha$ or $\mathrm{I} \kappa \mathrm{B} \beta)$ in the proteasome and hence prevents the translocation of $\mathrm{NF}-\kappa \mathrm{B}$ from the cytosol into the nucleus. ${ }^{4-7}$ Thus calpain inhibitor I prevents the expression (for example, after exposure to endotoxin) of many $\mathrm{NF}-\kappa \mathrm{B}$ dependent genes, including those for the inducible isoforms of nitric oxide synthase $(\mathrm{iNOS})^{8-10}$ and cyclooxygenase (COX-2). ${ }^{11}{ }^{12}$

Reactive oxygen species (ROS) and nitrogen species have been implicated as mediators of disruption of the intestinal barrier in inflammatory bowel diseases (IBDs) but their molecular targets and pathways have not been defined. ${ }^{13-19}$ In addition to ROS, overproduction of nitric oxide (NO) due to expression of iNOS also plays an important role in various models of inflammation. ${ }^{20}{ }^{21} \mathrm{NO}$ has been postulated to play a dual role in the gastrointestinal tract. Continuous release of $\mathrm{NO}$ from a constitutive NO synthase, which is located in intestinal epithelial and lamina propria cells, neuronal terminals, and endothelial cells, is involved in the physiological maintenance of motility, tone, permeability, and tissue blood flow. ${ }^{22}$ On the other hand, overwhelming production of NO by iNOS have been postulated to have a pathological role in IBD. Numerous clinical reports have demonstrated elevated levels of nitrite in rectal dialysates and increased iNOS activity in colon biopsies of patients affected by Crohn's diseases or ulcerative colitis. ${ }^{161522} 23$ Animal models of IBD have provided evidence that colitis is associated with increased expression or activity of iNOS and that inhibitors of NOS activity have anti-inflammatory effects. ${ }^{24-28} \mathrm{Re}-$ cent data suggest that the damaging effects of

Abbreviations used in this paper: $\mathrm{NF}-\kappa \mathrm{B}$, nuclear factor $\kappa \mathrm{B}$; iNOS, inducible nitric oxide synthase; COX, cyclooxygenase; ROS, reactive oxygen species; IBD, inflammatory bowel disease; NO, nitric oxide; PARP, poly (ADP-ribose) polymerase; DNBS, dinitrobenzene sulphonic acid; PBS, phosphate buffered saline; ICAM-1, intercellular adhesion molecule 1; MPO, myeloperoxidase; PMN, polymorphonuclear leucocyte; MDA, malondialdehyde. 
$\mathrm{NO}$ in various forms of inflammation are mediated, at least in part, by peroxynitrite, a potent oxidant produced by the reaction of NO and superoxide anion. ${ }^{29}{ }^{30}$ Peroxynitrite is cytotoxic via a number of independent mechanisms, including (i) initiation of lipid peroxidation, (ii) inactivation of a variety of enzymes (most notably mitochondrial respiratory enzymes and membrane pumps), ${ }^{31}$ and (iii) depletion of glutathione. ${ }^{32}$ Moreover, peroxynitrite can also cause DNA damage ${ }^{33}$ resulting in activation of the nuclear enzyme poly (ADP-ribose) polymerase (PARP; also known as poly(ADP-ribose) synthetase, PARS), depletion of NAD and ATP, and ultimately cell death. ${ }^{35}$ Indeed, DNA from colon biopsy specimens of patients with ulcerative colitis has significantly increased levels of 8-hydroxyguanine, 2-hydroxyadenine, 8-hydroxyadenine, and 2,6-diamino-5-formamidopyrimidine. ${ }^{3637}$ Activation of PARP may also play an important role in various experimental models of inflammation, including colitis. ${ }^{38-42}$ In this condition, pharmacological inhibition or gene targeted disruption of PARP appears to exert beneficial effects. ${ }^{43-47}$

The complex role of NO in the physiology and pathology and the cytotoxic potential of ROS in the gastrointestinal tract have directed research to the investigation of pharmacological tools to neutralise the cytotoxic effects of $\mathrm{NO}$ and/or ROS without interfering with the physiological roles of $\mathrm{NO}^{48}$

There is evidence that inhibition of calpain I activity reduces the injury associated with ischaemia-reperfusion of the brain, ${ }^{49-51}$ liver, ${ }^{52}$ and heart ${ }^{53-56}$

Here we investigate the effects of calpain inhibitor I on the inflammatory response (colitis) caused by intracolonic administration of 2,4,6-dinitrobenzene sulphonic acid (DNBS). In particular, we investigated the effects of calpain inhibitor I on the colon injury associated with DNBS induced colitis. In order to gain a better insight into the mechanism of action of calpain inhibitor I, we also investigated its effects on expression of iNOS, and COX-2 protein (immunohistochemistry) and activity, and peroxynitrite formation and activation of the nuclear enzyme PARP (by immunohistochemistry).

\section{Methods}

ANIMALS

Male Sprague-Dawley rats (300-350 g; Charles River, Milan, Italy) were housed in a controlled environment and provided with standard rodent chow and water. Animal care complied with Italian regulations on protection of animals used for experimental and other scientific purpose (DM 116192) as well as with EEC regulations (OJ of ECL 358/1 12/18/ 1986)

EXPERIMENTAL GROUPS

In the treated group of animals, calpain inhibitor I was given daily as an intraperitoneal bolus of $5 \mathrm{mg} / \mathrm{kg}$ (DNBS+Calp group). In the vehicle treated group of rats, vehicle (saline) was given instead of calpain inhibitor I (DNBS group). In
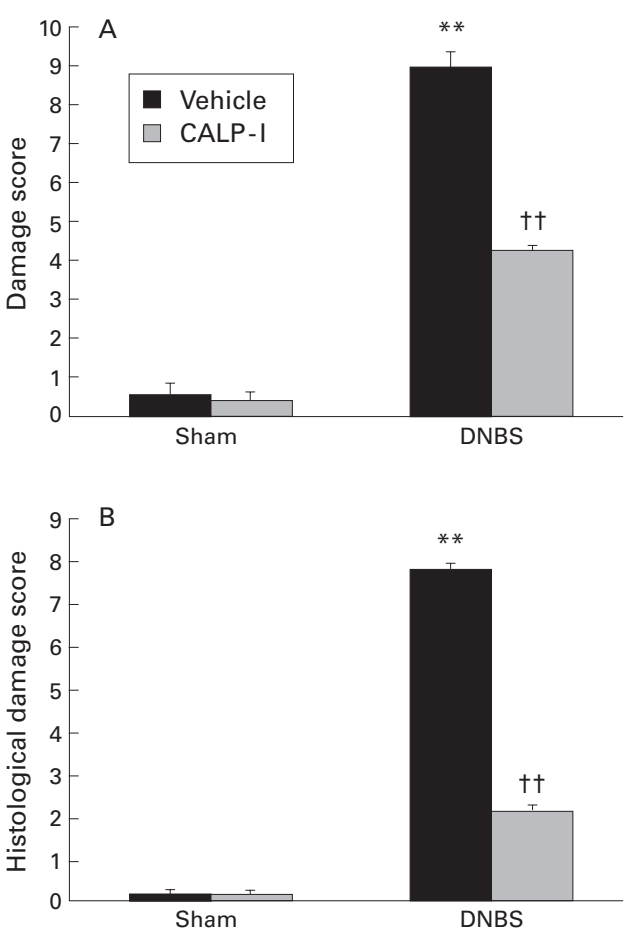

Figure 1 Effects of calpain inhibitor I (CALP-1) on the macroscopic damage score $(A)$ and microscopic histological score (B). Colon damage was scored by two independent observers. Values are mean (SEM) of data obtained from 10 rats in each group. ${ }^{\star *} p<0.01 \mathrm{v}$ sham; $t_{t}<0.01 \mathrm{v}$ dinitrobenzene sulphonic acid (DNBS).

separate groups of rats, surgery was performed in an identical manner as in the DNBS group except that saline was injected instead of DNBS (sham group). In an additional group of animals, sham surgery was combined with administration of calpain inhibitor I (dose as above) (sham+Calp).

\section{INDUCTION OF EXPERIMENTAL COLITIS}

Colitis was induced using the technique of acid induced colon inflammation, as described previously. ${ }^{27}$ In fasted rats lightly anaesthetised with isoflurane, a $3.5 \mathrm{~F}$ catheter was inserted into the colon via the anus until approximately the splenic flexure (8 cm from the anus). DNBS $(25 \mathrm{mg} / \mathrm{rat})$ was dissolved in $50 \%$ ethanol (total volume $0.8 \mathrm{ml}$ ). Thereafter the animals were kept for 15 minutes in a Trendelenburg position to avoid reflux. Seven animals (sham colitis) received an enema with vehicle alone ( $50 \%$ ethanol, $0.8 \mathrm{ml})$. After colitis and sham colitis induction, the animals were observed for three days. On day 4, the animals were weighed and anaesthetised with chloral hydrate $(400 \mathrm{mg} / \mathrm{kg}$ intraperitoneally), and the abdomen was opened by a midline incision. The colon was removed, freed from surrounding tissues, opened along the antimesenteric border, rinsed, weighed, and processed for histology and immunohistochemistry. In an additional experiment, colitis and sham colitis were induced in 28 rats (seven animals/group). Animals were monitored for evaluation of mortality for seven days.

The macroscopic damage score was assessed according to Wallace and colleagues. ${ }^{57}$ 

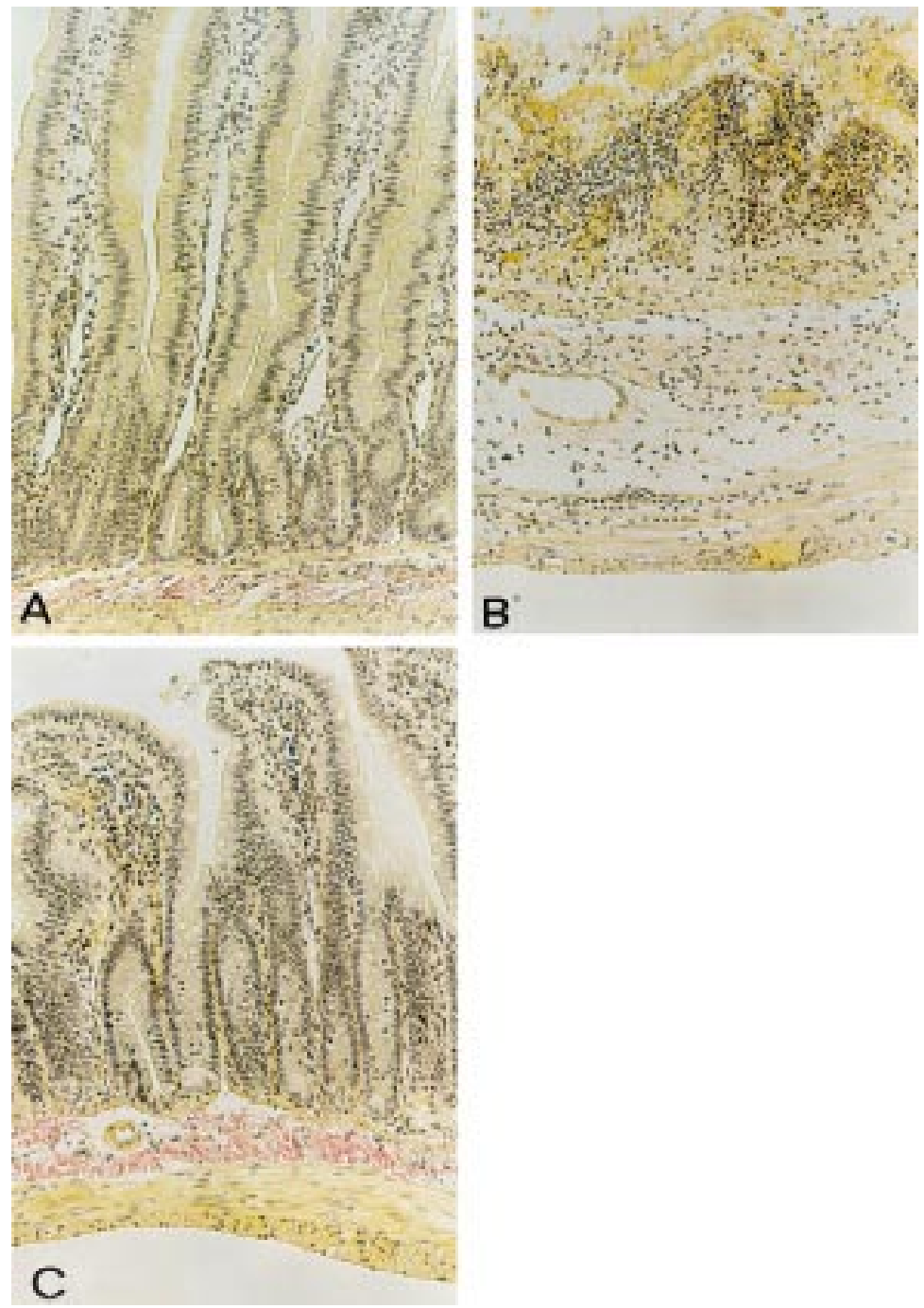

Figure 2 Effects of calpain inhibitor I on colon injury. No histological modification was observed in the mucosa of sham operated rats $(A)$. Mucosal injury was produced after dinitrobenzene sulphonic acid (DNBS) administration, characterised by the absence of epithelium and massive mucosal and submucosal infiltration with inflammatory cells (B). Treatment with calpain inhibitor $I(C)$ corrected the disturbances in morphology associated with DNBS administration. Original magnification $\times 120$. The figure is representative of at least three experiments performed on different experimental days.

LIGHT MICROSCOPY

After fixation for one week at room temperature in Dietrich solution $(14.25 \%$ ethanol, $1.85 \%$ formaldehyde, $1 \%$ acetic acid), samples were dehydrated in graded ethanol and embedded in Paraplast (Sherwood Medical, Mahwah, New Jersey, USA). Thereafter, $7 \mu \mathrm{m}$ sections were deparaffinised with xylene, stained with haematoxylin-eosin and trichromic van Giesson's stain, and evaluated with a Dialux 22 Leitz (Wetziar, Germany) microscope. Colon damage was scored by two independent observers, as described previously, ${ }^{58}{ }^{59}$ according to the following morphological criteria: 0 , no damage; 1, localised hyperaemia without ulcers; 2, linear ulcers with no significant inflammation; 3 , linear ulcers with inflammation at one site; 4 , two or more major sites of inflammation and ulceration extending $>1 \mathrm{~cm}$ along the length of the colon; and $6-8$, one point is added for each centimetre of ulceration beyond an initial $2 \mathrm{~cm}$.
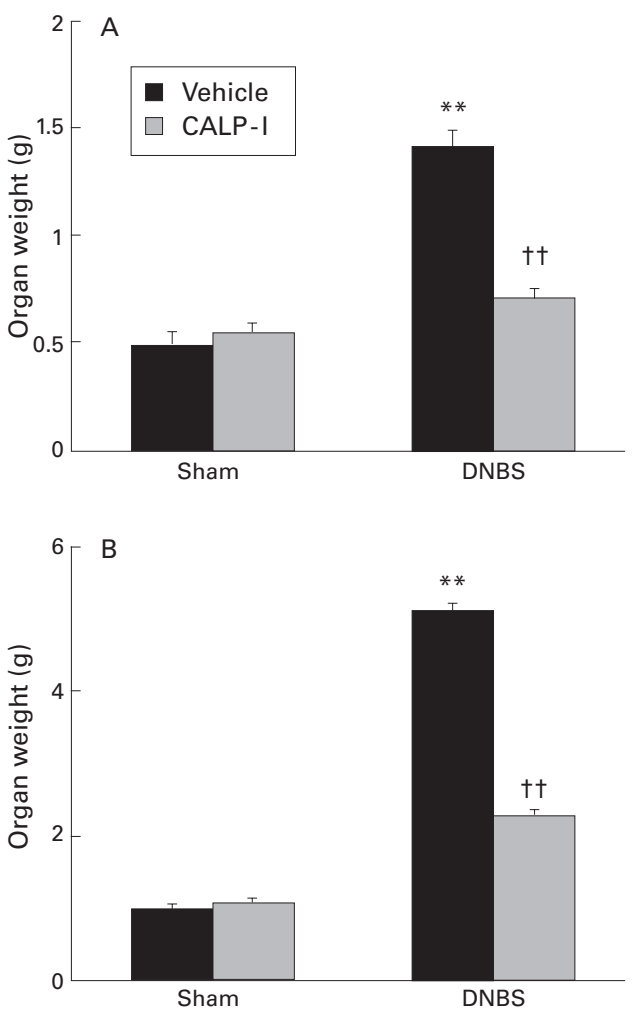

Figure 3 Organ weight. A significant increase in weight in the spleen $(A)$ and colon $(B)$ was consistently seen four days after dinitrobenzene sulphonic acid (DNBS) injection. The weight of the organs was significantly reduced in rats who had been treated with calpain inhibitor I (CALP-1). Values are mean (SEM) of 10 rats in each group. ${ }_{* *} p<0.01$ v sham; $t+p<0.01 v D N B S$.

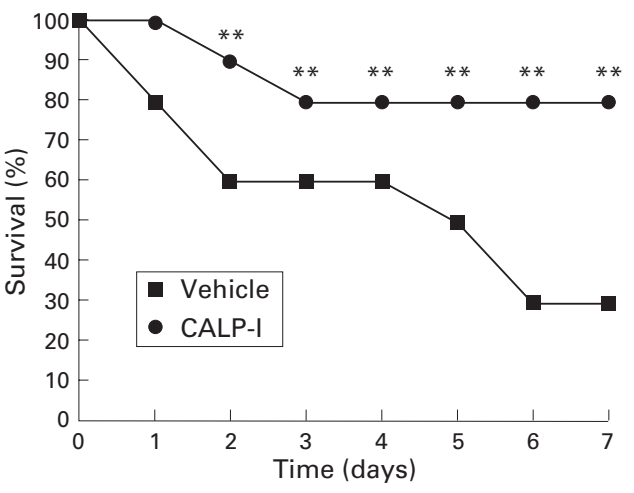

Figure 4 Effect of calpain inhibitor I (CALP-1) treatment on dinitrobenzene sulphonic acid (DNBS) induced mortality. Survival is significantly improved in $C A L P-1$ treated rats in comparison with the high mortality rate of the DNBS treated rats. $n=10$ rats in each group. ${ }^{* *} p<0.01 v D N B S$.

LOCALISATION OF NITROTYROSINE, PARP, P-SELECTIN, ICAM-1, iNOS, AND COX-2 BY IMMUNOFLUORESCENCE

Indirect immunofluorescence staining was performed on $7 \mu \mathrm{m}$ thick sections of unfixed colon of the rat. Sections were cut with a Slee and London cryostat at $-30{ }^{\circ} \mathrm{C}$, transferred onto clean glass slides, and dried overnight at room temperature. Sections were permeabilised with acetone at $-20^{\circ} \mathrm{C}$ for 10 minutes and rehydrated in phosphate buffered saline (PBS; 150 $\mathrm{mM} \mathrm{NaCI}, 20 \mathrm{mM}$ sodium phosphate, $\mathrm{pH}$ 7.2) at room temperature for 45 minutes. Sections 


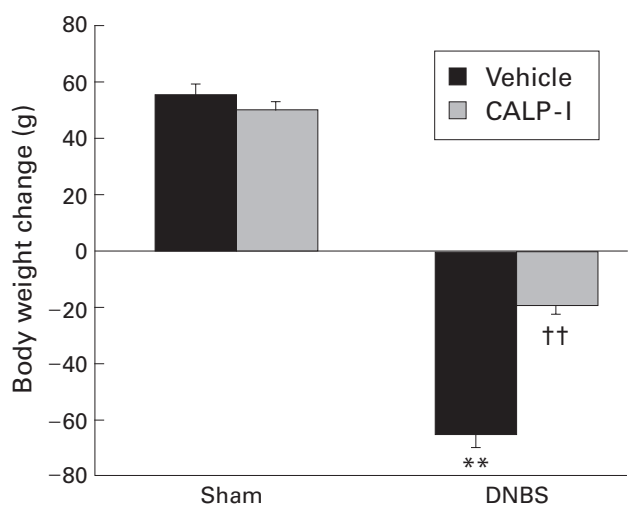

Figure 5 Effect of calpain inhibitor I (CALP-1) treatment on changes in body weight four days after dinitrobenzene sulphonic acid (DNBS) intracolonic administration. Body weight was recorded immediately before DNBS

administration and at the end of the experimental period.

$C A L P-1$ treatment significantly prevented the loss in body weight. Values are mean (SEM) of 10 rats in each group. ${ }_{*}^{*} p<0.01$ v sham; $+t p<0.01$ v DNBS.

were coincubated overnight with: (1) antinitrotyrosine rabbit polyclonal antibody (1:500 in PBS, v/v) or with anti-poly (ADP-ribose) goat polyclonal antibody rat $(1: 500$ in $\mathrm{PBS}, \mathrm{v} / \mathrm{v}) ;(2)$ primary anti-iNOS antibody (1:500 in PBS, $\mathrm{v} / \mathrm{v}$ ) or anti-COX-2 antibody (1:500 in PBS, $\mathrm{v} / \mathrm{v}$ ); or (3) rabbit antihuman polyclonal antibody directed at P-selectin (CD62P) which reacts with rat and mouse antirat antibody directed at intercellular adhesion molecule 1 (ICAM-1) (CD54) (1:500 in PBS, v/v) (DBA, Milan, Italy). Sections were washed with PBS and co-incubated with secondary antibody (TRITC conjugated antigoat) and FITC conjugated antirabbit (Jackson, West Grove, Pennsylvania, USA) antibody (1:80 in PBS, $\mathrm{v} / \mathrm{v}$ ) for two hours at room temperature. Sections were washed as before, mounted with $90 \%$ glycerol in PBS, and observed with a Nikon RCM8000 confocal microscope equipped with a $40 \times$ oil objective.

MYELOPEROXIDASE ACTIVITY

Myeloperoxidase (MPO) activity, an indicator of polymorphonuclear leucocyte (PMN) accumulation, was determined as previously described.$^{60}$ Four days after intracolonic injection of DNBS the colon was removed and weighed. The colon was homogenised in a solution containing $0.5 \%$ hexa-decyl-trimethyl-ammonium bromide dissolved in $10 \mathrm{mM}$ potassium phosphate buffer $(\mathrm{pH} 7)$ and centrifuged for 30 minutes at $20000 \mathrm{~g}$ at $4^{\circ} \mathrm{C}$. An aliquot of the supernatant was then allowed to react with a solution of tetra-methyl-benzidine $(1.6 \mathrm{mM})$ and $0.1 \mathrm{mM} \mathrm{H} \mathrm{H}_{2} \mathrm{O}_{2}$. The rate of change in absorbance was measured spectrophotometrically at $650 \mathrm{~nm}$. MPO activity was defined as the quantity of enzyme degrading $1 \mu \mathrm{mol}$ of peroxide/minute at $37^{\circ} \mathrm{C}$ and was expressed in milliunits per gram weight of wet tissue.

MALONDIALDEHYDE (MDA) MEASUREMENT Levels of malondialdehyde (MDA) in the colon were determined as an indicator of lipid peroxidation. ${ }^{61}$ Four days after intracolonic injection the colon was removed, weighed, and

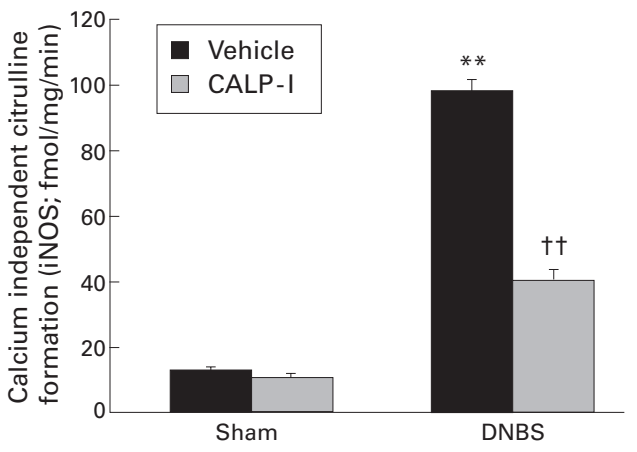

Figure 6 Effect of calpain inhibitor I (CALP-1) treatment on inducible nitric oxide synthase (iNOS) activity four days after dinitrobenzene sulphonic acid (DNBS) intracolonic administration. DNBS

administration induced a significant increase in iNOS activity. CALP-1 treatment significantly reduced $i N O S$ activity. Values are mean (SEM) of 10 rats in each group. ${ }^{\star *} p<0.01$ v sham; $++p<0.01$ v DNBS.

homogenised in $1.15 \% \mathrm{KCl}$ solution. An aliquot $(100 \mu \mathrm{l})$ of the homogenate was added to a reaction mixture containing $200 \mu \mathrm{l}$ of $8.1 \%$ sodium dodecyl sulphate, $1500 \mu \mathrm{l}$ of $20 \%$ acetic acid ( $\mathrm{pH} 3.5), 1500 \mu \mathrm{l}$ of $0.8 \%$ thiobarbituric acid, and $700 \mu$ of distilled water. Samples were boiled for one hour at $95^{\circ} \mathrm{C}$ and centrifuged at $3000 \mathrm{~g}$ for 10 minutes. Absorbance of the supernatant was measured spectrophotometrically at $650 \mathrm{~nm}$.

DETERMINATION OF NITRIC OXIDE SYNTHASE ACTIVITY

The calcium independent conversion of L-arginine to L-citrulline in the homogenates of the colon (obtained three days after DNBS treatment in the presence or absence of calpain inhibitor I) served as an indicator of iNOS activity. ${ }^{62}$ Tissues were homogenised in buffer composed of $50 \mathrm{mM}$ Tris $\mathrm{HCl}, 0.1 \mathrm{mM}$ EDTA, and $1 \mathrm{mM}$ phenylmethylsulphonyl fluoride $(\mathrm{pH}$ 7.4) on ice using a tissue homogeniser. Conversion of $\left[{ }^{3} \mathrm{H}\right]$-L-arginine to $\left[{ }^{3} \mathrm{H}\right]$-L-citrulline was measured in homogenates as described previously. ${ }^{63}$ Briefly, homogenates $(30 \mu \mathrm{l})$ were incubated in the presence of $\left[{ }^{3} \mathrm{H}\right]$-L-arginine (10 $\mu \mathrm{M}, 5 \mathrm{kBq}$ per tube), NADPH $(1 \mathrm{mM})$, calmodulin $(30 \mathrm{nM})$, tetrahydrobiopterin (5 $\mu \mathrm{M})$, and EGTA $(2 \mathrm{mM})$ for 20 minutes at $22^{\circ} \mathrm{C}$. Reactions were stopped by dilution with $0.5 \mathrm{ml}$ of ice cold HEPES buffer ( $\mathrm{pH} 5.5$ ) containing EGTA $(2 \mathrm{mM})$ and EDTA $(2 \mathrm{mM})$. Reaction mixtures were applied to Dowex 50W $\left(\mathrm{Na}^{+}\right.$form) columns and the eluted $\left[{ }^{3} \mathrm{H}\right]-\mathrm{L}-$ citrulline activity was measured by a Beckman scintillation counter.

MATERIALS

Biotin blocking kit, biotin conjugated goat antirabbit IgG, and avidin-biotin peroxidase complex were obtained from Vector Laboratories (Burlingame, California, USA). Primary antinitrotyrosine antibody was purchased from Upstate Biotech (Saranac Lake, New York, USA). Primary P-selectin (CD62P) and ICAM-1 (CD54) were purchased from Pharmingen (DBA, Milan, Italy). All other reagents and compounds used were purchased from Sigma Chemical Company (St Louis, Missouri, USA). 

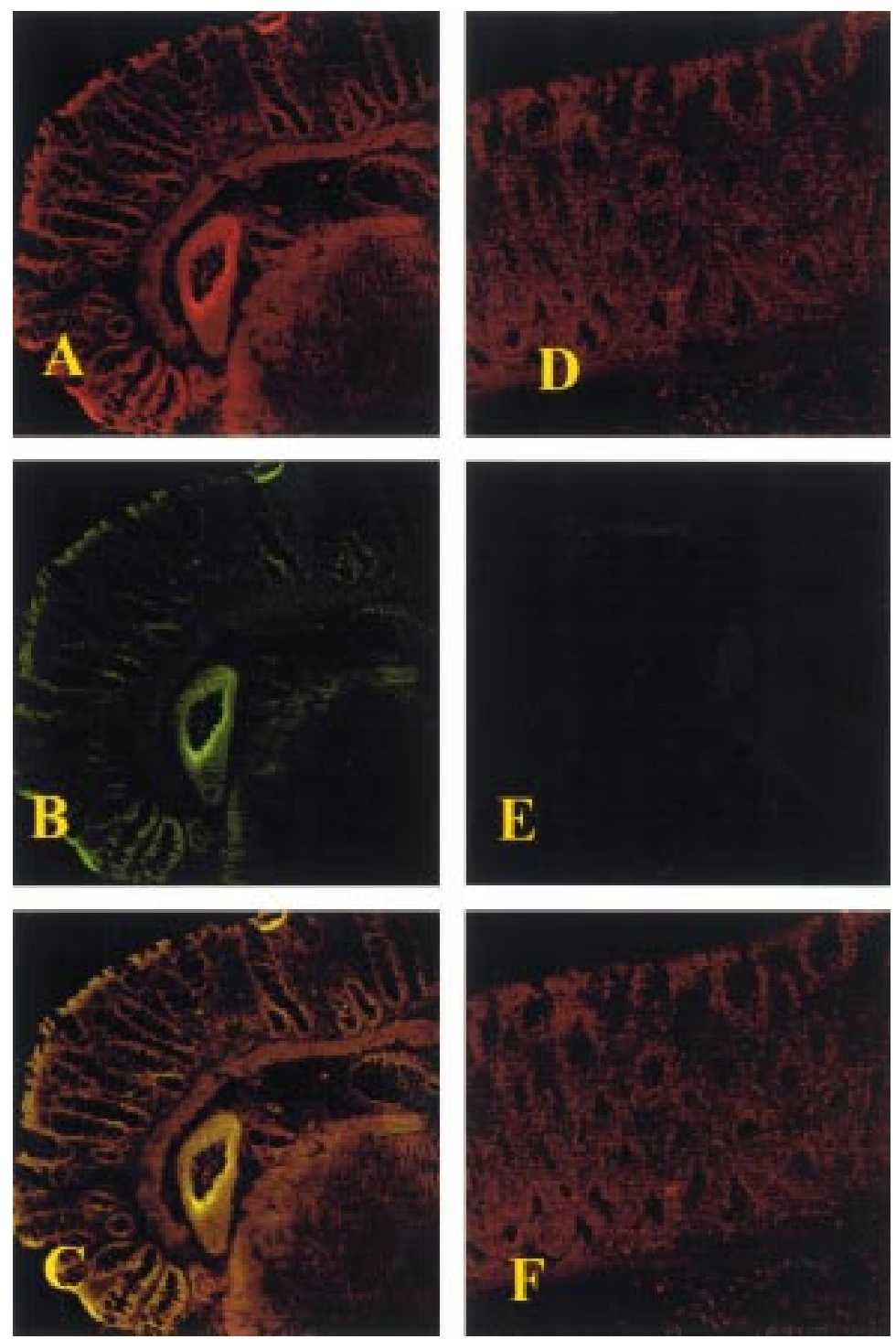

Figure 7 Immunohistochemical localisation for cyclooxygenase $2(C O X-2)$ and inducible nitric oxide synthase ( $i N O S$ ) in the colon. Immunohistochemical staining for $\operatorname{COX}(A)$ and $i N O S(B)$ showed positive staining localised in the injured area from dinitrobenzene sulphonic acid (DNBS) treated rats. The intensity of the observed staining for COX (D) and $i N O S(E)$ was significantly reduced in the colon from calpain inhibitor I treated rats. $(C)$ and $(F)$ represent the staining combination of $(A-B)$ and $(D-E)$, respectively. Original magnification $\times 145$. The figure is representative of at least three experiments performed on different experimental days.

DATA ANALYSIS

All values in the figures and text are expressed as mean (SEM) of $\mathrm{n}$ observations. For the in vivo studies, $\mathrm{n}$ represents the number of animals studied. In the experiments involving histology or immunohistochemistry, the figures shown are representative of at least three experiments performed on different experimental days. The results were analysed by one way ANOVA followed by a Bonferroni post hoc test for multiple comparisons. A p value $<0.05$ was considered significant

\section{Results}

EFFECTS OF CALPAIN INHIBITOR I ON THE DEGREE OF COLITIS (HISTOLOGY)

Four days after intracolonic administration of DNBS, the colon appeared flaccid and filled with liquid stool. Macroscopic inspection of the caecum, colon, and rectum showed the presence of mucosal congestion, erosion, and haemorrhagic ulcerations (see fig 1A). The histopathological features included transmural necrosis and oedema, and diffuse leucocyte cellular infiltrate in the submucosa (fig $1 \mathrm{~B}$, 2B). Inflammatory changes of the intestinal tract were associated with an increase in the weight of the colon (fig 3B). Treatment of rats with calpain inhibitor I significantly attenuated the extent and severity of the histological signs of colon injury (figs 1, 2C, 3B). A significant increase in the weight of the spleen, an indicator of inflammation, was also noted in vehicle treated rats who had received DNBS (fig 3A). No significant increase in weight of either the colon or spleen was observed in DNBS rats who had been treated with calpain inhibitor I (fig 3). Survival of the animals was monitored for seven days. DNBS rats who received vehicle developed severe haemorrhagic diarrhoea, and $40 \%$ and $80 \%$ of these animals died within two and six days, respectively, after DNBS administration. In contrast, only $20 \%$ of rats who had been treated with calpain inhibitor I had haemorrhagic diarrhoea and died (fig 4). The surviving rats appeared to be healthy and showed mild diarrhoea.

EFFECTS OF CALPAIN INHIBITOR I ON CHANGES IN BODY WEIGHT

In vehicle treated rats, severe colitis caused by DNBS was associated with a significant loss in body weight (fig 5). Treatment of DNBS rats with calpain inhibitor I significantly reduced the loss in body weight.

EFFECT OF CALPAIN INHIBITOR I ON NITRIC OXIDE PRODUCTION AND COX-2 EXPRESSION

In the colons obtained from animals subjected to DNBS induced colitis, a significant increase in iNOS activity was detected at four days (fig $6)$. iNOS activity was significantly $(p<0.01)$ lower in DNBS rats treated with calpain inhibitor I (fig 6). Four days after DNBS treatment, colon sections were obtained to determine immunohistological staining for iNOS and COX-2. While there was negligible staining in intestinal sections from control animals (data not shown), immunohistochemical analysis, using specific anti-iNOS and antiCOX-2 antibodies, revealed positive staining primarily localised in the infiltrated inflammatory cells and in disrupted epithelial cells (fig $7 \mathrm{~A}, \mathrm{~B}$ respectively). As demonstrated in fig $7 \mathrm{C}$, positive staining for iNOS and COX-2 protein was colocalised in inflammatory cells and in disrupted epithelial cells. Calpain inhibitor I reduced the degree of immunostaining for iNOS and COX-2 in the colon of DNBS treated rats (fig $7 \mathrm{D}-\mathrm{F}$ ).

EFFECT OF CALPAIN INHIBITOR I ON

NITROTYROSINE FORMATION AND PARP ACTIVITY To determine localisation of "peroxynitrite formation" and/or other nitrogen derivatives produced during colitis, nitrotyrosine, a specific marker of nitrosative stress, ${ }^{29}$ was measured by immunohistochemical analysis in the distal colon. Four days after DNBS treatment, sections of colon were obtained to 

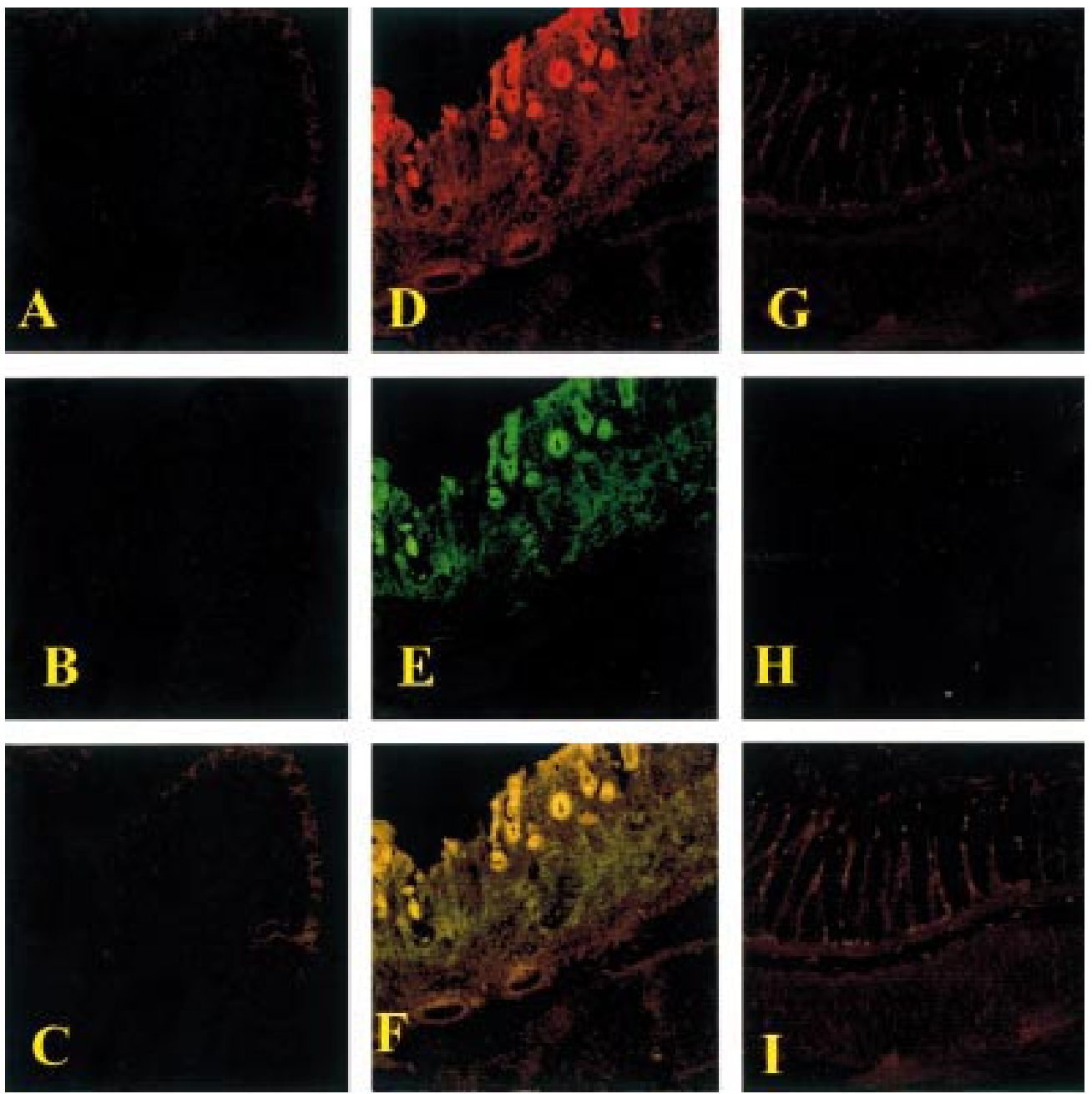

Figure 8 Immunohistochemical localisation of nitrotyrosine and poly (ADP-ribose) polymerase (PARP) in the colon. No positive staining for nitrotyrosine $(A)$ or $P A R P(B)$ was found in colon sections from sham operated rats.

Immunohistochemical staining for nitrotyrosine (D) and $P A R P(E)$ showed positive staining localised in the injured area from a dinitrobenzene sulphonic acid (DNBS) treated rat. The intensity of the staining for nitrotyrosine (G) and PARP $(H)$ was significantly reduced in the ileum from calpain inhibitor I treated rats. $(C),(F)$, and $(I)$ represent the staining combination of $(A-B),(D-E)$, and $(G-H)$, respectively. Original magnification $\times 145$. The figure is representative of at least three experiments performed on different experimental days.

determine immunohistological staining for PARP. Sections of colon from sham administered rats did not stain for nitrotyrosine or PARP (fig 8A, 8B). Colon sections obtained from vehicle treated DNBS rats exhibited positive staining for nitrotyrosine and PARP (fig $8 \mathrm{D}, \mathrm{E})$ which was colocalised in inflammatory cells and in disrupted epithelial cells. Calpain inhibitor I reduced the degree of immunostaining for nitrotyrosine and PARP in the colon of DNBS treated rats (fig $8 \mathrm{G}-\mathrm{I}$ ).

EFFECT OF CALPAIN INHIBITOR I ON

MYELOPEROXIDASE ACTIVITY AND LIPID

PEROXIDATION IN THE COLON

Colitis caused by DNBS was also characterised by an increase in MPO activity, an indicator of infiltration (accumulation) of the colon with PMNs (fig 9A). This finding is consistent with light microscopy findings that showed that the colon of vehicle treated DNBS rats contained a large number of PMNs. Infiltration of leucocytes into the mucosa has been suggested to contribute significantly to tissue necrosis and mucosal dysfunction associated with colitis as activated PMNs release large amounts of free radicals. The increase in MPO activity in the colon correlated positively with the increase in tissue levels of MDA, indicating an increase in lipid peroxidation (fig 9B). Treatment of DNBS rats with calpain inhibitor I, however, significantly reduced both the degree of PMN infiltration (determined as an increase in MPO activity) and the associated lipid peroxidation (increase in tissue MDA levels) (fig 9).

EFFECT OF CALPAIN INHIBITOR I ON P-SELECTIN AND ICAM-1 EXPRESSION

To elucidate the effects of calpain inhibitor I on neutrophil accumulation in inflamed colon, we evaluated intestinal expression of ICAM- 1 and $\mathrm{P}$-selectin. Tissue sections obtained from sham operated rats stained with an anti-ICAM-1 antibody showed specific staining along the vessels (see arrows), demonstrating that ICAM-1 is expressed constitutively in endothelial cells (fig 10A). After DNBS administration, staining intensity substantially increased in vessels (see arrows) of the lamina propria. Immunohistochemical staining for 



Figure 9 Effect of calpain inhibitor I (CALP-1) on neutrophil infiltration and lipid peroxidation. malondialdehyde (MDA) levels (B) in the colon from dinitrobenzene sulphonic acid (DNBS) treated rats. MPO activity and $M D A$ levels were significantly increased in $D N B S$ treated rats in comparison with sham controls. CALP-1 treated rats showed a significant reduction in $M P O$ activity and MDA levels. Values are mean (SEM) of 10 rats in each group. ${ }^{\star *} p<0.01 \mathrm{v}$ sham; $\dagger+p<0.01 \mathrm{v}$ DNBS.

ICAM-1 was also present in epithelial cells of injured colon and in infiltrated inflammatory cells in damaged tissues from DNBS treated rats (see small arrows in fig 10D). Sections from calpain inhibitor I treated rats did not reveal upregulation of constitutive ICAM-1, which was expressed in the endothelium along the vascular wall (fig 10G). No positive staining was observed in tissue sections obtained from sham operated rats that were stained with an antibody against P-selectin (fig 10B). In contrast, tissue sections of the colon obtained from DNBS treated rats showed positive staining for P-selectin localised in the vascular endothelium (see arrows in fig 10E). Tissue sections obtained from calpain inhibitor I treated rats, however, exhibited no staining for $\mathrm{P}$-selectin (fig $10 \mathrm{H}$ ). As can be seen in fig $10 \mathrm{E}$, positive staining for P-selectin and ICAM-1 was (co-) localised in the endothelium.

\section{Discussion}

IBD is a multifactorial disorder of unknown aetiology. There is however good evidence that enhanced formation of reactive oxygen or nitrogen species contributes to the pathophysiology of IBD. For example, monocytes from patients with Crohn's disease ${ }^{64}$ and PMNs from patients with ulcerative colitis ${ }^{65}$ have an increased capacity to generate free oxygen radicals. Furthermore, advanced stages of bowel inflammation in humans ${ }^{16} 172223$ and animals $^{24-28}$ are associated with enhanced (local) formation of NO by iNOS. We have demonstrated for the first time that calpain inhibitor I attenuates: (i) colon injury (histology), (ii) infiltration of the colon with PMNs (histology and MPO activity), and (iii) degree of lipid peroxidation in the colon caused by DNBS in the rat. These findings support the view that calpain inhibitor I exerts potent antiinflammatory effects and that this agent may be useful in the therapy of IBD.

What then are the mechanism(s) by which calpain inhibitor I inhibits the inflammation caused by injection of DNBS? There is good evidence that production of ROS such as hydrogen peroxide, superoxide, and hydroxyl radicals at the site of inflammation contributes to tissue damage. ${ }^{29}{ }^{30-42}$ Inhibitors of NOS activity reduce colon injury in experimental models of IBD suggesting a role for NO in the pathophysiology associated with this model of inflammation. ${ }^{48}{ }^{66}$ Activation of the transcription factor NF- $\kappa \mathrm{B}$ plays an important role in expression of iNOS. ${ }^{67-70}$ Our study demonstrated that calpain inhibitor I attenuated expression of iNOS in the colon of DNBS treated rats (figs 6,7D). Therefore, we propose that the reduction by calpain inhibitor I of expression of iNOS may contribute to the antiinflammatory effects of this agent. Enhanced formation of NO (by iNOS) in the presence of superoxide anions leads to generation of the oxidant peroxynitrite. We demonstrated that calpain inhibitor I attenuated nitration of proteins (determined by nitrotyrosine formation by immunohistochemistry) in the colon of rats with DNBS induced colitis (fig 8G). Nitrotyrosine formation, together with its detection by immunostaining, was initially proposed as a relatively specific marker for detection of the endogenous formation "footprint" of peroxynitrite. ${ }^{71}$ There is however recent evidence that certain other reactions can also induce tyrosine nitration; for example, reaction of nitrite with hypochlorous acid and MPO with hydrogen peroxide can lead to the formation of nitrotyrosine.$^{72}$ Increased nitrotyrosine staining is therefore considered an indication of "increased nitrosative stress" rather than a specific marker of generation of peroxynitrite. Nevertheless, our results are consistent with the hypothesis that prevention of expression of iNOS by calpain inhibitor I in turn results in reduced formation of $\mathrm{NO}$ and subsequently peroxynitrite in the colon of DNBS treated rats.

In common with iNOS, expression of COX-2 is also mediated by transcription factor $\mathrm{NF}-\kappa \mathrm{B}$. We have reported here that calpain inhibitor I also attenuated expression of COX-2 protein in inflammatory cells located in the colon of DNBS treated rats. There is good evidence in this and other models of inflammation that enhanced formation of prostanoids following induction of COX-2 contributes to the pathophysiology of local inflammation ${ }^{73} 74$ and also that selective inhibitors of COX-2 exert potent anti-inflammatory effects. ${ }^{75-77} \mathrm{We}$ have demonstrated that expression of COX-2 protein was increased in the colon of DNBS 

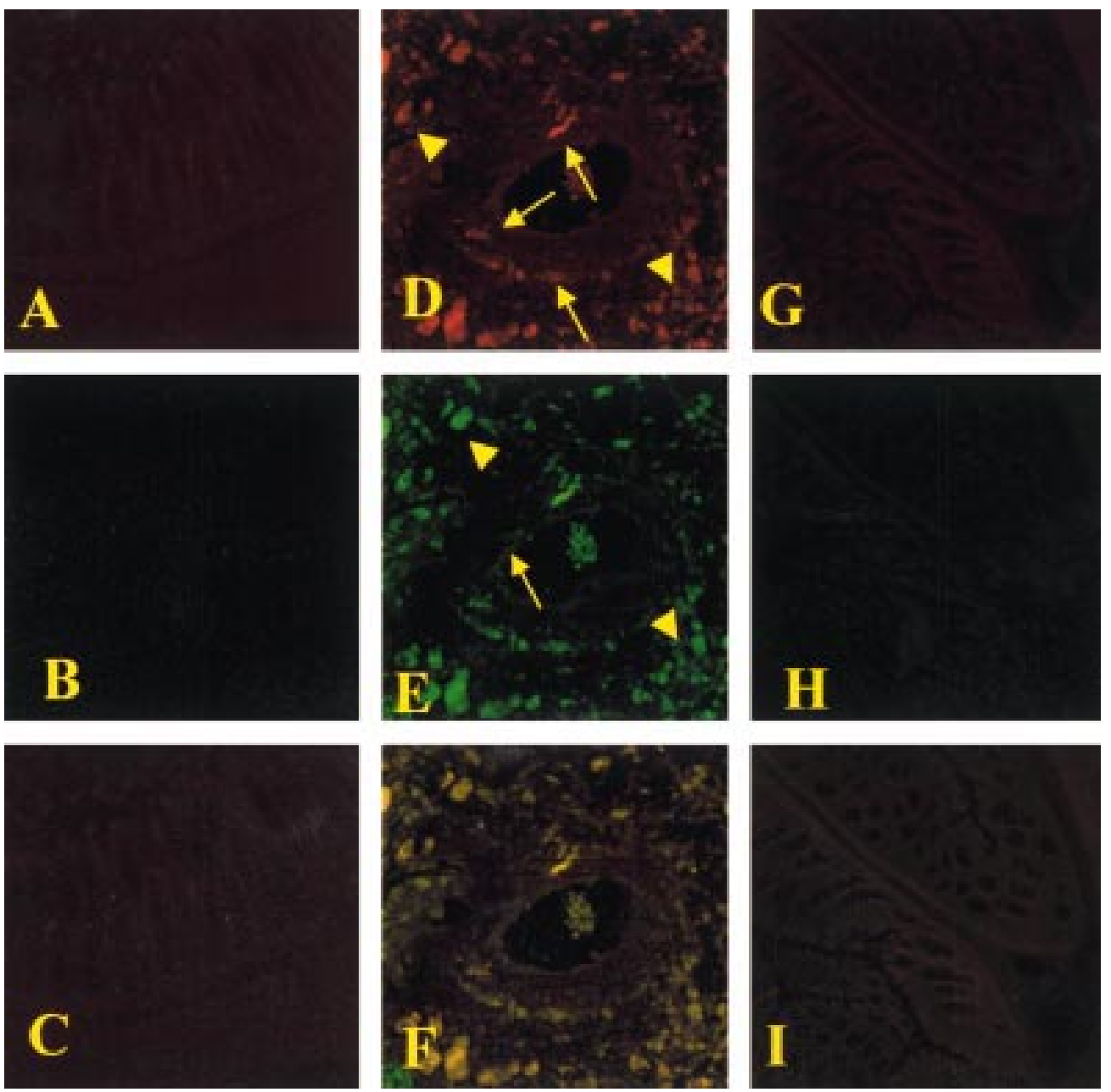

Figure 10 Immunohistochemical localisation of P-selectin in the colon. Staining of colon sections obtained from sham operated rats with anti-intercellular adhesion molecule 1 (ICAM-1) antibody showed specific staining along vessels, demonstrating that ICAM-1 is constitutively expressed ( $A$ ). Ileum sections from sham operated rats revealed no positive staining for P-selectin (B). Sections obtained from dinitrobenzene sulphonic acid (DNBS) treated rats showed intense positive staining for ICAM-1 (D) and P-selectin (E) on endothelial cells. The degree of endothelial staining for ICAM-1 $(G)$ and $P$-selectin $(H)$ was markedly reduced in tissue sections obtained from calpain inhibitor I treated rats. $(C),(F)$, and $(I)$ represent the staining combination of $(A-B),(D-E)$, and $(G-H)$ respectively. Original magnification $\times 145$. The figure is representative of at least three experiments performed on different experimental days.

treated rats. Thus we propose that the observed anti-inflammatory effects of calpain inhibitor I in experimental colitis are, at least in part, due to prevention of expression of COX-2. Indeed, selective inhibitors of COX-2 activity exert potent anti-inflammatory effects in various models of inflammation. ${ }^{75-77}$

ROS and peroxynitrite produce cellular injury and necrosis via several mechanisms, including peroxidation of membrane lipids, protein denaturation, and DNA damage. ROS produce strand breaks in DNA which trigger energy consuming DNA repair mechanisms and activate the nuclear enzyme PARP. Activation of PARP results in depletion of its substrate NAD and also in a reduction in the rate of glycolysis. As NAD functions as a cofactor in glycolysis and the tricarboxylic acid cycle, NAD depletion leads to a rapid fall in intracellular ATP. This process has been termed "the PARP or PARS suicide hypothesis". ${ }^{35}$ There is recent evidence that activation of PARP may also play an important role in inflammation..$^{38-42}$ We have demonstrated in this study that the increase in PARP activity caused by DNBS in the colon was attenuated by pretreatment of rats with calpain inhibitor I (fig $8 \mathrm{H}$ ). Thus it is possible that prevention by calpain inhibitor I of activation of PARP contributes to the anti-inflammatory effects of this agent in experimental colitis.

There is little information on the role of calpain(s) in "classical models" of inflammation. Ischaemia and reperfusion of tissues as well as trauma lead to local or (even) systemic inflammatory responses. Interestingly, both ischaemia-reperfusion as well as tissue trauma cause activation of calpain. ${ }^{78-80}$ We have recently discovered that haemorrhage and resuscitation (but not haemorrhage alone) leads to a significant increase in calpain activity (of the heart) which is abolished by the dose of calpain inhibitor I used here (McDonald, Cuzzocrea, Thiemermann, unpublished). Thus it is possible that prevention of calpain activity contributes to the beneficial effects of calpain inhibitor I, the colitis caused by DNBS in the rat. There is good evidence that inhibition of calpain I activity also reduces the injury associated with ischaemia-reperfusion of the brain, ${ }^{81-84}$ liver, ${ }^{85} 86$ 


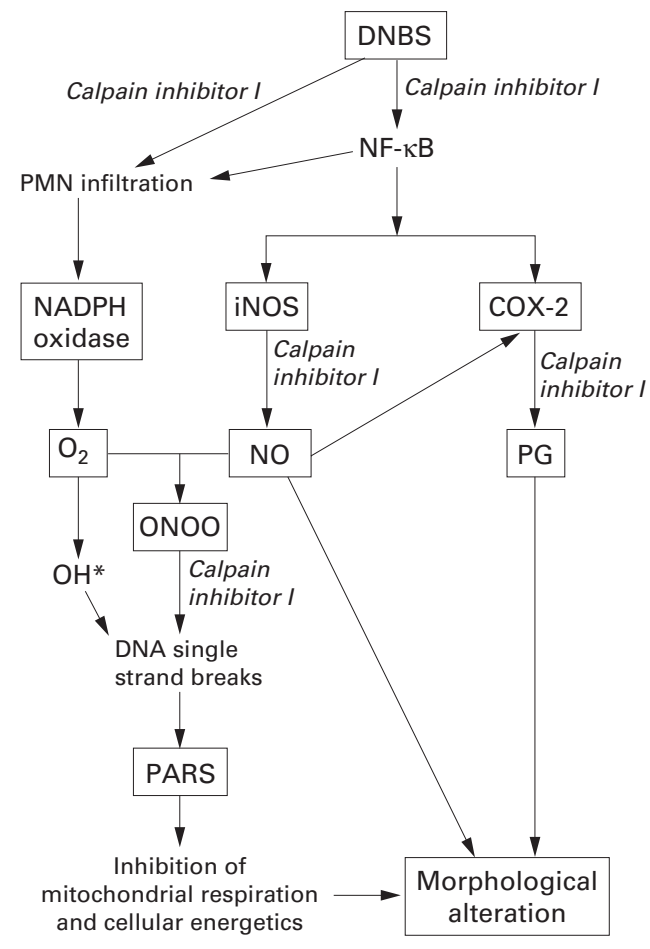

Figure 11 Proposed scheme of some of the delayed inflammatory pathways involving nitric oxide (NO*), hydroxyl radical $\left(\mathrm{OH}^{\star}\right)$, and peroxynitrite $(\mathrm{ONOO})$ in dinitrobenzene sulphonic acid (DNBS) induced colitis, and potential sites of the anti-inflammatory actions of calpain inhibitor I. DNBS triggers expression of inducible nitric oxide (NO) synthase (iNOS), at least in part, via activation of nuclear factor $\kappa B(N F-\kappa B)$. NO in turn combines with superoxide to form ONOO-. Hydroxyl radical (produced from superoxide via the iron catalysed Haber-Weiss reaction) and ONOO- or peroxynitrous acid $(\mathrm{ONOOH})$ induce cellular injury. Part of the injury is related to the development of DNA single strand breakage, with consequent activation of poly (ADP-ribose) polymerase (PARP), leading to cellular dysfunction. Expression of the inducible isoform of cyclooxygenase $(C O X-2)$ is also dependent on activation of NF- $\kappa B$. In addition, NO can directly increase the catalytic activity of COX-2, leading to enhanced production of

proinflammatory prostaglandin metabolites. We propose that the anti-inflammatory effects of calpain inhibitor I may include (1) inhibition of activation of $N F-\kappa B$ and prevention of expression of $i N O S$ and COX-2, (2) inhibition of ONOO formation, and (3) prevention of activation of PARP (see discussion for further explanations).

and heart. ${ }^{78} 87-90$ The mechanism by which inhibitors of calpain activity protect tissues/ organs against reperfusion injury and/or the associated inflammation is not entirely clear. Calpain acts on several substrates causing proteolytic modifications of proteins which results in changes in their biochemical and morphological parameters. Activation of calpain results in proteolysis of several cellular proteins, mostly associated with the cellular membrane, including cytoskeletal proteins (for example, spectrin, fodrin, and microtubule associated proteins), membrane proteins (for example, growth factor receptors, adhesion molecules, and ion transporters), enzymes (kinases, phosphatases, and phospholipases), as well as cytokines and transcription factors. Although many of these are implicated in the pathophysiology of ischaemia-reperfusion injury, the exact role of calpain activation in inflammation is still unclear and warrants further investigation.
In conclusion, our study demonstrated that the degree of colitis caused by injection of DNBS was substantially reduced by treatment of rats with calpain inhibitor I. Hence we report for the first time that calpain inhibitor I exerts potent anti-inflammatory effects in vivo. The mechanisms of the anti-inflammatory effect of calpain inhibitor I are not entirely clear. Calpain inhibitor I inhibits activation of NF- $\mathrm{NB}$ (positive feedback; fig 11), which mediates expression of iNOS and COX-2 protein and activity, and ultimately the degree of peroxynitrite formation and tissue injury. In addition, calpain inhibitor I inhibits the formation of P-selectin and ICAM-1, which in turn may contribute to recruitment of PMNs. Our findings suggest that calpain inhibitor I treatment may be useful in conditions associated with local or systemic inflammation, including IBD.

This study was supported by a grant from $40 \%$. The authors would like to thank Giovanni Pergolizzi and Carmelo La Spada for their excellent technical assistance during this study, Mrs Caterina Cutrona for secretarial assistance, and Miss Valentina Malvagni for editorial assistance. CT is a senior fellow of the British Heart Foundation (FS 96/018).

1 Melloni E, Pontremoli S. The calpains. Trends Neurosci 1989;12:438-44.

2 Saido TC, Sorimachi H, Suzuki K. Calpain: new perspectives in molecular diversity and physiological-

pathophysiological involvement. FASEB F 1994;8:814-22.
Wang KK, Yuen PW. Calpain inhibition: an overview of its therapeutic potential. Trends Pharmacol Sci 1994;15:41219.

4 Baeuerle PA, Baltimore D. Activation of DNA-binding activity in an apparently cytoplasmic precursor of the NF-kappa B transcrip

5 Brown K, Park S, Kanno T, et al. Mutual regulation of the ranscription activator NF-kappa B and its inhibitor, I kappa B. Proc Natl Acad Sci USA 1993;90:2532-6.

6 Henkel T, Machleidt T, Alkalay I, et al. Rapid proteolysis of IкB- $\alpha$ is necessary for activation of transcription factor NF-кB. Nature 1993;365:182-5.

7 Siebenlist U, Franzoso G, Brown K. Structure, regulation and function of NF-kappa B. Annu Rev Cell Biol 1994;10:405-55.

8 Griscavage JM, Wilk S, Ignarro LJ. Inhibitors of proteosome pathway interfere with induction of nitric oxide synthase in macrophages by blocking activation of transcription factor NF-kappa B. Proc Natl Acad Sci USA 1996;93:3308-12.

9 Kengatharan M, De Kimpe SJ, Thiemermann C. Analysis of the signal transduction in the induction of nitric oxide synthase by lipoteichoic acid in macrophages. Br f Pharmasynthase by lipoteichoic
col 1996;117:1163-70.

10 Milligan SA, Owens MW, Grisham MB. Inhibition of IkappaB-alpha and Ikappa-B-beta proteolysis by calpain inhibitor I blocks nitric oxide synthase synthesis. Arch Biochem Biophys 1996;335:388-95.

11 Yamamoto K, Arakawa T, Ueda N, et al. Transcriptional roles of nuclear factor kappa $\mathrm{B}$ and nuclear factorinterleukin- 6 in the tumor necrosis factor-alpha-dependent induction of cyclooxygenase-2 in MC3T3-E1 cells. $\mathcal{F}$ Biol Chem 1995;270:31315-20.

12 Crofford LJ, Tan B, McCarthy CJ, et al. Involvement of nuclear factor kappa $\mathrm{B}$ in the regulation of cyclooxygenase- 2 expression by interleukin-1 in rheumatoid synoviocytes. Arthritis Rheum 1997;40:226-36.

13 Simmonds NJ, Alien RE, Stevens TRJ, et al. Chemiluminescence assay of mucosal reactive oxygen metabolites in inflammatory bowel disease. Gastroenterology 1992;103: inflamm.

14 Grisham MB. Oxidants and free radicals in inflammatory bowel disease. Lancet 1994;344:859-61.

15 Rachmilewitz D, Stamier JS, Karmeli F, et al. Peroxynitritenduced rat colitis - a new model of colon inflammation. Gastroenterology 1993;105:1681-8.

16 Middleton SJ, Shorthouse M, Hunter JD. Increased nitric oxide synthesis in ulcerative colitis. Lancet 1993;341:465-6.

17 Boughton-Smith NK, Evans SM, Hawkey CJ, et al. Nitric oxide synthase activity in ulcerative colitis and Crohn's disease. Lancet 1993;341:338-40.

18 Miller MJS, Thompson JH, Zhang XJ, et al. Role of inducible nitric oxide synthase expression and peroxynitrite formation in guinea pig ileitis. Gastroenterology 1995;109: $1475-83$.

19 Salzman AL. Nitric oxide in the gut. N Horizons 1995;3:3345.

20 Cuzzocrea S, Zingarelli B, Gilard E, et al. AntiCuzzocrea S, Zingarelli B, Gilard E, et al. Anti-
inflammatory effects of mercaptoethylguanidine, a cominflammatory effects of mercaptoethylguanidine, a comscavenger, in carrageenan-induced models of inflamma-
tion. Free Radic Biol Med 1998;24:450-9. 
21 Moncada S, Palmer RMJ, Higgs EA. Nitric oxide: physiology, pathophysiology and pharmacology. Pharmacol physiology, pathophy

22 Nathan C. Nitric oxide as a secretory product of mammalian cells. FASEB F 1996;6:3051-64.

23 Lundberg JO, Hellstrom PM, Lundberg JM, et al. Greatly increased luminal nitric oxide in ulcerative colitis. Lancet 1994;344:1673-4.

24 Ikeda I, Kasajima T, Ishiyama S, et al. Distribution of inducible nitric oxide synthase in ulcerative colitis. $A m \mathcal{F}$ Gastroenterol 1997;92:1339-41.

25 Aiko S, Grisham MB. Spontaneous intestinal inflammation and nitric oxide metabolism in HLA-B27 transgenic rats. Gastroenterology 1995;109:142-50.

26 Ribbons KA, Zhang XJ, Thompson JH, et al. Potential role of nitric oxide in a model of chronic colitis in rhesus maeof nitric oxide in a model of chronic colitis
aques. Gastroenterology 1995;109:1475-83.

27 Miller MJS, Thompson JH, Zhang XJ, et al. Role of inducible nitric oxide synthase expression and peroxynitrite formation in guinea pig ileitis. Gastroenterology 1995;109: 1475-83.

28 Mourelle M, Vilaseca J, Guarner F, et al. Toxic dilatation of colon in a rat model of colitis is linked to an inducible form of nitric oxide synthase. Am F Physiol 1996;33:G425-30.

29 Rachmilewitz D, Karmeli F, Okon E. Sulhydryl blockerinduced rat colon inflammation is ameliorated by inhibition of nitric oxide synthase. Gastroenterology 1995;109:98tion

30 Beckman JS, Beckman TW, Chen J, et al. Apparent hydroxyl radical production by peroxynitrite: implication for endothelial injury from nitric oxide and superoxide. Proc Nat Acad Sci USA 1990;87:1620-4.

31 Szabò C. The role of peroxynitrite in the pathophysiology of shock, inflammation and ischemia-reperfusion injury. Shock 1996;6:79-88.

32 Crow JP, Beckman JS. The role of peroxynitrite in nitric oxide-mediated toxicity. Curr Top Microbiol Immunol 1995; 196:57-73.

33 Phelps DT, Ferro TJ, Higgins PJ, et al. TNF-alpha induces peroxynitrite-mediated depletion of lung endothelial glu-
tathione via protein kinase C. Am $\mathcal{F}$ Physiol 1995;269: tathione

34 Inoue S, Kawanishi S. Oxidative DNA damage induced by simultaneous generation of nitric oxide and superoxide. FEBS Lett 1995;371:86-8.

35 Salgo MG, Bermudez E, Squadrito G, et al. DNA damage and oxidation of thiols peroxynitrite causes in rat thymocytes. Arch Biochem Biophys 1995;322:500-5.

36 Zingarelli $\mathrm{B}$, O'Connor $\mathrm{M}$, Wong $\mathrm{H}$, et al. Peroxynitritemediated DNA strand breakage activates poly-ADP ribosyl synthetase and causes cellular energy depletion in macrophages stimulated with bacterial lipopolysaccharide. F Immunol 1996;156:350-8.

37 Wiseman H, Halliweil B. Damage to DNA by reactive oxygen and nitrogen species: role in inflammatory disease and gen and nitrogen species: role in inflammatory dis
progression to cancer. Biochem $\mathcal{F} 1996 ; 313: 17-29$

38 Lih-Brody L, Powell SR, Collier KP, et al. Increased oxidative stress and decreased antioxidant defenses in mucosa of inflammatory bowel disease. Dig Dis Sci 1996;41:2078-86.

39 Szabó C, Lim LHK, Cuzzocrea S, et al. Inhibition of poly (ADP-ribose) synthetase exerts anti-inflammatory effects and inhibits neutrophil recruitment. F Exp Med 1997;186: 1041-9.

40 Szabó C, Viràg L, Cuzzocrea S, et al. Protection against peroxynitrite-induced fibroblast injury and arthritis development by inhibition of poly (ADP-ribose) synthetase. Proc opment by inhibition of poly (ADP-rib

41 Cuzzocrea S, Caputi AP, Zingarelli B. Peroxynitritemediated DNA strand breakage activates poly (ADP-
ribose) synthetase and causes cellular energy depletion in ribose) synthetase and causes cellular energy depletion in
carrageenan-induced pleurisy. Immunology 1998;93:96101 .

42 Cuzzocrea S, Zingarelli B, Gilard E, et al. Protective effects of 3-aminobenzamide, an inhibitor of poly (ADP-ribose) synthase in carrageenan-induced models of local inflammation. Eur F Pharmacol 1998;342:67-76.

43 Zingarelli B, Szabo C, Salzman AL. Blockade of poly(ADPribose) synthetase inhibits neutrophil recruitment, oxidant generation, and mucosal injury in murine colitis. Gastroenterology 1999;16:335-45.

44 Zingarelli B, Cuzzocrea S, Zsengeller Z, et al. Inhibition of poly (ADP ribose) synthetase protects against myocardial ischemia and reperfusion injury. Cardiovasc Res 1997;36: 205-12.

45 Thiemermann C, Bowes J, Myint FP, et al. Inhibition of the activity of poly(ADP ribose) synthase reduces ischemiareperfusion injury in the heart and skeletal muscle. Proc Natl Acad Sci USA 1997;94:679-83.

46 Cuzzocrea S, Zingarelli B, Costantino G, et al. Beneficial effects of 3-aminobenzamide, an inhibitor of poly (ADPribose) synthetase in a rat model of splanchnic artery
occlusion and reperfusion. Brf Pharmacol 1997;121:106574.

47 Eliasson IVUL, Sampei K, Mandir AS, et al. Poly(ADPribose) polymerase gene disruption renders mice resistan to cerebral ischemia. Nat Med 1997;3:1090-5.

48 Zingarelli B, Szab C, Salzman AL. Reduced oxidative and nitrosative damage in murine experimental colitis in the absence of inducible nitric oxide synthase. Gut 1999;45: 199-209.

49 Bartus RT, Elliott PJ, Hayward NJ, et al. Calpain as a novel target for treating acute neurodegenerative disorders. Neurol Res 1995;17:249-58.
50 Wang KK, Nath R, Posner A, et al. An alphamercaptoacrylic acid derivative is a selective nonpeptide
cell-permeable calpain inhibitor and is neuroprotective. cell-permeable calpain inhibitor and is
Proc Natl Acad Sci USA 1996;93:6687-92.

51 Markgraf CG, Velayo NL, Johnson MP, et al. Six-hour window of opportunity for calpain inhibition in focal cerebral ischemia in rats. Stroke 1998;29:152-8.

52 Kohli V, Madden JF, Bentley RC, et al. Calpain mediates ischemic injury of the liver through modulation of apoptosis and necrosis. Gastroenterology 1999;116:168-78.

53 Atsma DE, Bastiaanse EM, Jerzewski A, et al. Role of calcium-activated neutral protease (calpain) in cell death in cultured neonatal rat cardiomyocytes during metabolic inhibition. Circ Res 1995;76:1071-8.

54 Yoshida K, Inui M, Harada K, et al. Reperfusion of rat heart after brief ischemia induces proteolysis of calspectin by calpain. Circ Res 1995;77:603-10.

55 Yoshida K, Yamasaki Y, Kawashima S. Calpain activity alteres rat myocardial subfractions after ischemia and reperfusion. Biochem Biophys Acta 1993;1182:215-20.

56 Iwamoto $\mathrm{H}$, Miura $\mathrm{T}$, Okamura $\mathrm{T}$, et al. Calpain inhibitor I reduces infarct size and DNA fragmentation of myocardium in ischemic/reperfused hearts. F Cardiovasc Res 1999; 33:580-6.

57 Wallace JL, Keenan CM, Gale D, et al. Exacerbation of experimental colitis by non-steroidal antinflammatory drugs is not related to elevated leukotriene B4 synthesis. Gastroenterology 1992;102:18-27.

58 Morrs GP, Bek PL, Herridge MS, et al. Hapten-induced model of chronic inflammation and ulceration in the rat. Gastroenterology 1989;96:795-803.

59 Zingarell B, Squadrito F, Graziani P, et al. Effects of zileuton, a new 5-lipoxygenase inhibitor, in experimentally induced colitis in rats. Agents Actions 1993;39:150-6.

60 Mullane KM, Kraemer R, Smith B. Myeloperoxidase activity as a quantitative assessment of neutrophil infiltration into ischemic myocardium. F Pharmacol Methods 1985;14: 157-67.

61 Ohkawa H, Ohishi N, Yagi K. Assay for lipid peroxides in animal tissues by thiobarbituric acid reaction. Anal Biochem 1979;95:351-8

62 Szabó C, Mitchell JA, Thiemermann C, et al. Nitric oxidemediated hyporeactivity to norepinephrine precedes the induction of nitric oxide synthase in endotoxin shock. $B r f$ Pharmacol 1993;108:786-94.

63 Heller B, Wang ZQ, Wagner EF, et al. Inactivation of the poly(ADP-ribose) polymerase gene affects oxygen radical and nitric oxide toxicity in islet cells. $\mathcal{F}$ Biol Chem 1995;270: 11176 .

64 Kitahora T, Suzuki IR, Asakura H, et al. Active oxygen species generated by monocytes and polymorphonuclear cells in patients in Crohn's disease. Dig Dis Sci 1998;33:951-5.

65 Shiratora Y, Acki S, Takada H, et al. Oxygen-derived free radical generating capacity of polymorphonuclear cells in patients with ulcerative colitis. Digestion 1989;44:163-71.

66 Zingarelli B, Cuzzocrea S, Szabó C, et al. Mercaptoethylguanidine, a combined inhibitor of nitric oxide synthase and peroxynitrite scavenger, reduces trinitrobenzene sulfonic acid-induced colon damage in rats. $\mathcal{F}$ Pharmacol Exp Ther 1998;287:1048-55.

67 Xie Q, Kashiwabara Y, Nathan C. Role of transcription factor NF-B/Rel in induction of nitric oxide. 7 Biol Chem 1994;269:4705-8.

68 Griscavage JM, Wilk S, Ignarro LJ. Serine and cysteine proteinase inhibitors prevent nitric oxide production by activated macrophages by interfering with transcription of inducible NO synthase gene. Biochem Biophys Res Commun 1995;215:721-9.

69 Ruetten H, Thiemermann C. Effect of calpain inhibitor I, an inhibitor of the proteolysis of I kappa B, on the circulatory failure and multiple organ dysfunction caused by endotoxin in the rat. Br f Pharmacol 1997;121:695-704.

70 Liu ZQ, Kunimatsu M, Yang JP, et al. Proteolytic processing of nuclear factor kappa B by calpain in vitro. FEBS Lett 1996;385:109-13.

71 Beckman JS. Oxidative damage and tyrosine nitration from peroxynitrite. Chem Res Toxicol 1996;9:836-44.

72 Eiserich JP, Hristova M, Cross CE, et al. Formation of nitric oxide-derived inflammatory oxidants by myeloperoxidase in neutrophils. Nature 1998;391:393-7.

73 Salvemini D, Manning PZ, Zweifel BS, et al. Dual inhibition of nitric oxide and prostaglandin production contributes to the antiinflammatory properties of nitric oxide synthase inhibitors. F Clin Invest 1995;196:307.

74 Sautebin L, Ialenti A, Di Rosa M. Relationship between nitric oxide and prostaglandins in carrageenin pleurisy. Biochem Pharmacol 1998;55:1113.

75 Mitchell JA, Akarasereenont P, Thiemermann C, et al. Selectivity of nonsteroidal antiinflammatory drugs as nhibitors of constitutive and inducible cyclooxygenase. Proc Natl Acad Sci USA 1993;24:11693.

76 Harada Y, Hatanaka K, Kawamura M, et al. Role of prostaglandin $\mathrm{H}$ synthase-2 in prostaglandin $\mathrm{E}_{2}$ formation in rat carrageenin-induced pleurisy. Prastaglandin 1996;51:1933.

77 Futaki N, Aral I, Hamasaka Y, et al. Selective inhibition of NS-398 on prostanoid production in inflamed tissue in rat carrageenan-air-pouch inflammation. 7 Pharm Pharmacol 1993;45:753-5.

78 Yoshida K, Inui M, Harada K, et al. Reperfusion of rat heart after brief ischemia induces proteolysis of calspectin by calpain. Circ Res 1995;77:603-10. 
79 Sorimachi Y, Harada K, Saido TC, et al. Downregulation of calpastatin in rat heart after brief brain ischemia and reper$7 ; 122: 743-8$

80 Kampfl A, Posmantur RM, Zhao X, et al. Mechanisms of calpain proteolysis following traumatic brain injury: implications for pathology and therapy: a review and update. $\mathcal{F}$ Neurotrauma 1997;4:121-34.

81 Rami A, Krieglstein J. Protective effects of calpain inhibitors against neuronal damage caused by cytotoxic hypoxia in vitro and ischemia in vivo. Brain Res 1993;609:67-70.

82 Bartus RT, Elliott PJ, Hayward NJ, et al. Calpain as a novel target for treating acute neurodegenerative disorders. $\mathrm{Neu}$ rol Res 1995; 7:249-58.

83 Wang KK, Nath R, Posner A, et al.. An alphamercaptoacrylic acid derivative is a selective nonpeptide cell-permeable calpain inhibitor and is neuroprotective. Proc Natl Acad Sci USA 1996;3:6687-92.

84 Markgraf CG, Velayo NL, Johnson MP, et al. Six-hour window of opportunity for calpain inhibition in focal cerebral ischemia in rats. Stroke 1998;29:152-8.
85 Kohli V, Gao W, Camargo CA, et al. Calpain is a mediator of preservation-reperfusion injury in rat liver transplanta-

86 Kohli V, Madden JF, Bentley RC, et al. Calpain mediates ischemic injury of the liver through modulation of apoptosis and necrosis. Gastroenterology 1999;116:168-78

87 Toda G, Matsushita S, Kuramoto K, et al. Calciumactivated neutral protease inhibitor (E-64c) and reperfusion from experimental myocardial infarction. Ipn Heart f 1989;30:375-86.

88 Atsma DE, Bastiaanse EM, Jerzewski A, et al. Role of calcium-activated neutral protease (calpain) in cell death in cultured neonatal rat cardiomyocytes during metabolic inhibition. Circ Res 1995;76:1071-8.

89 Yoshida K, Yamasaki Y, Kawashima S. Calpain activity alters rat myocardial subfractions after ischemia and reperfusion. Biochem Biophys Acta 1993;1182:215-20.

90 Matsumura Y, Kusuoka H, Inoue M, et al. Protective effect of the protease inhibitor leupeptin against myocardial stunof the protease inhibitor leupeptin against myocar
ning. f Cardiovasc Pharmacol 1993;22:135-42.

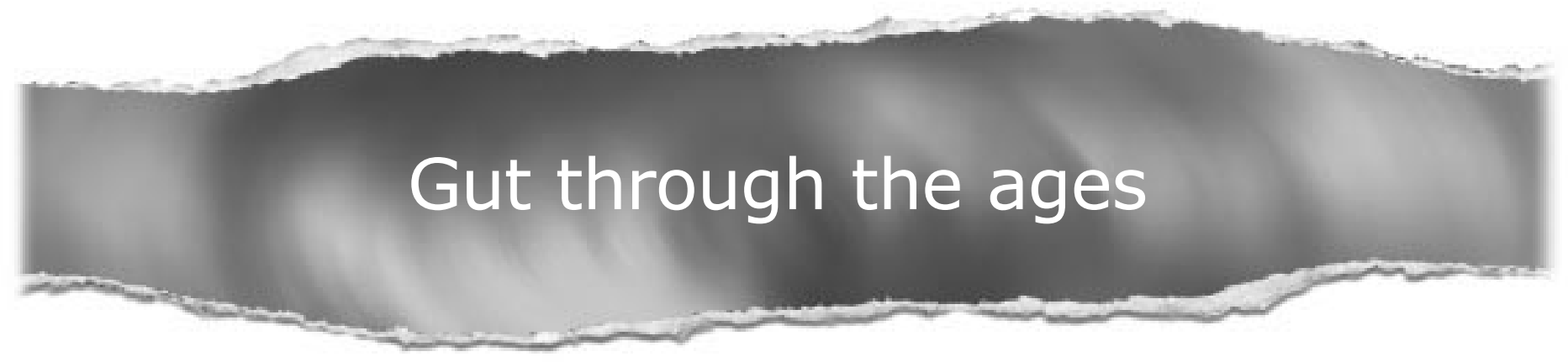

Browse the Archive

Gut online has an archive of content dating back to 1966.

Full text from 1997; abstracts from 1975; table of contents from 1966

www.gutjnl.com 